\title{
Atypical Variants of Mycosis Fungoides
}

\section{(1) Dursun Dorukhan Altınıșık, (1) Özge Așkın, (1) Tuğba Kevser Uzunçakmak, (i) Burhan Engin}

Istanbul University-Cerrahpasa, Cerrahpasa Faculty of Medicine, Department of Dermatology, Istanbul, Turkey

\section{ABSTRACT}

Mycosis fungoides (MF) is the most common type of cutaneous T-cell lymphoma (CTCL) and it is characterised by specific histological features. MF is in a spectrum of disorders which includes Sezary syndrome and other CTCL subtypes. Clinically and histopathologically it can imitate other T-cell mediated dermatosis hence making its diagnosis difficult. Due to different prognosis and difference in treatment strategies other subtypes of CTCL must be differentiated from MF. MF is a clinically indolent low-grade lymphoma which is seen in people aged between 5560 and it's seen more commonly in men (2:1 ratio). Meanwhile other subtypes of MF like folliculotropic variant may show relatively a more aggressive course and our treatment strategy may differ.

Keywords: Mycosis fungoides, Cutaneous T-cell lymphoma, Phototherapy, PUVA

\section{Introduction}

Mycosis fungoides (MF) is the most common type of cutaneous T-cell lymphoma (CTCL) and it is characterised by specific histological features [1]. MF is in a spectrum of disorders which includes Sezary syndrome and other CTCL subtypes. Clinically and histopathologically it can imitate other T-cell mediated dermatosis hence making its diagnosis difficult [2]. Due to different prognosis and difference in treatment strategies other subtypes of CTCL must be differentiated from MF. MF is a clinically indolent low-grade lymphoma which is seen in people aged between 55-60 and it's seen more commonly in men (2:1 ratio). Meanwhile other subtypes of MF like folliculotropic variant may show relatively a more aggressive course and our treatment strategy may differ $[3,4]$.

\section{MF Subtypes}

\section{Folliculotrophic MF (FMF)}

FMF has a broad spectrum of clinical presentations. Varying from patches, infiltrative plaques to tumours, prurigo nodularis or keratosis pilaris like lesions [5]. These lesions tend to contain the follicles frequently causing alopecia and in the paediatric population it tends to accompany hypopigmented patches and plaques. FMF preferentially involves the head and neck region however it can sometimes involve the trunk or the extremities [6]. Patients with FMF have significant pruritus which may be overlapped by S. aureus infection [7].

Histologically FMF presents with perifollicular infiltrates around the infundibulum sparing the bulbar region and the epidermis showing folliculotropism instead of epidermotropism. Immunohistochemistry shows in almost all cases a CD4+ phenotype. Clinical presentation of FMF depends upon the clinical presentation hence when located on the scalp it could cause alopecia which could be mistaken as alopecia areata, trichotillomania and cicatricial alopecias. It could present as follicular spiky papules resembling keratosis pilaris, lichen spinulosus, pitriasis rubra pilaris and lichen planopilaris. FMF is known as an aggressive variant of MF based on many series it is corelated with quick disease progression and worse outcome similar to tumour-stage MF. The estimated five-year survival is $94 \%$ for earlystage FMF while it's $69 \%$ for tumour-stage [8]. 
Management of FMF is based on it's aggressive behaviour and it is treated as such. Due to the perifollicular infiltrates being harder to target by skin-based therapies alone so it should be emphasized that narrow band UVB phototherapy cannot penetrate and target deep adnexal components of FMF hence psoralen and ultraviolet A (PUVA) is the first choice of treatment of early stages of FMF [9]. However, in later stages it could be combined with systemic retinoids like bexarotene or interferon (IFN). In late stages single agent chemotherapy like gemcitabine or histone deacetylase inhibitors like vorinostat and romidepsin may be used [10].

\section{Pagetoid Reticulosis (PG)}

PG or Woringer-Kolopp disease is a localised variant of MF. It is characterised by localised, slow growing patches or plaques located mainly at the distal extremities. These lesions are hyperkeratotic or psoriasiform in appearance. Histopathology shows a verrucous or psoriasiform hyperplasia with intraepidermal (pagetoid) diffusion of highly epidermotropic, abnormal lymphocytes seen in dispersed nests or throughout the epidermis. The neoplastic lymphocytes are $\mathrm{CD}^{+}$and express $\mathrm{CD} 4^{+/-}$and $\mathrm{CD} 8^{+/-}$. It is a benign disease which is treated locally with success by excision or radiotherapy [11].

\section{Granulomatous Slack Skin (GSS)}

GSS is an uncommon clinicopathological subtype of MF. It is characterised by slow growing of large, infiltrated drooping folds of atrophic skin in the intertriginous areas (axilla and groins).

Histopathology reveals many features resembling MF however the number of multifocal giant cells in GSS is larger displaying 20-30 nuclei per cell which is quite pathognomonic for GSS. Elastophagocytosis, elastic fibre loss and engulfment of lymphocytes are additional findings. Neoplastic lymphocytes mainly express $\mathrm{CD}^{+}$and $\mathrm{CD}^{+}$. Depending on the stage of the disease PUVA, topical mustard, radiotherapy and systemic chemotherapy can be used however patients with GSS need a lifelong observation for secondary lymphoid malignancies the main culprit being Hodgkin's disease [12].

\section{Granulomatous MF (GMF)}

Granulomatosis could be detected in many of the MF cases either as initial presentation or in later stages of the disease. The pathogenesis of granulomatosis in MF is unknown although it is known that in other disorders it is mediated by Th1 and Th2 cells. Treatment of CTCL with IFN or bexarotene might also induce granuloma formation. GMF is a histopathologic subtype of MF that may be found in histological sections from patients with classical, poikilodermous, hyperpigmented or FMF. In some instances the clinical characteristics may suggest granulomatous disease as it may mimic granuloma annulare or sarcoidosis. Pathologic criteria for GMF includes granuloma formation or numerous giant cells with histiocyte rich infiltration and loss of elastic fibres. Diagnosis of GMF may be difficult due to granulomatous component obscuring the abnormal lymphocytic infiltrate. Epidermotropism which is a major pathological evidence of MF may not be found in all cases [13].

GMF is associated with rapid disease progression and irresponsiveness to skin directed treatments so systemic treatment is a must. Individuals with GMF are also prone to developing secondary malignancies like Hodgkin's disease so frequent follow ups is a must [14].

\section{Poikilodermatous MF (PMF)}

Poikilodermous MF is a clinical variant of patch stage MF characterised by atrophy, telangiectasia and pigmentary changes. It is usually located around the gluteal region, breasts and hips and is frequently associated with classical and other subtypes of MF.

Histopathology reveal features of MF together with poikiloderma like epidermal atrophy, basal hydropic degeneration, pigment incontinence and telangiectasia. Immunophenotyping shows an overexpression of CD8+ cells. PMF is a mild variant of MF usually showing benign behaviour and responds to phototherapy [15].

\section{Hypopigmented MF (HMF)}

HMF is a variant of MF affecting people with dark skin and children or adolescents [16]. Hypopigmentation in HMF is due to loss of melanocytes in the lesional skin due to cytotoxic T-cells like in vitiligo. Clinical features of HMF includes irregular round shaped hypopigmented patches and plaques and this may be the only manifestation of MF or seen together with other variants like classical MF. In children the hypopigmented lesions may be accompanied by early folliculotrophic lesions. Histopathology reveals many similarities with classical MF, HMF is highly epidermotrophic composed of atypical lymphocytes, decreased melanin in stratum basale of the epidermis and melanophages. Compared to classical MF HMF is mainly composed of CD8+ lymphocytes [17].

Due to it's slow indolent course and it's lack of signs or symptoms multiple biopsies may be needed for definitive diagnosis. HMF is extremely responsive to phototherapy and resulting in favourable prognosis [16].

\section{Hyperpigmented MF (HPMF)}

HPMF is a rare subtype of MF seen mainly in darker individuals [18]. It presents itself with hyperpigmented patches or plaques with illdefined borders and variable amounts of scaling and skin atrophy. These lesions may be lone or accompanied by different types of MF. Histopathology shows features of classic MF together with vacuolar degeneration of basal keratinocytes and basal hydropic degeneration. Immunohistochemistry shows in most of the HPMF cases a $\mathrm{CD}^{+}$phenotype. These cytotoxic T-cells cause vacuolar 
degeneration resulting in interphase dermatitis and marked melanin incontinence. HPMF has an indolent clinical course similar to of early-stage MF with good response to phototherapy [19].

\section{MF Palmaris et Plantaris (MFPP)}

MFPP is a rare histopathologic variant of MF. Specific involvement of the palms and soles are seen in MFPP, these lesions tend to be bilateral and are characterised by erythematous hyperkeratotic patches and plaques covered in fissures or scales. These lesions may be accompanied by ulcerative lesions and dystrophic nails [20].

Histopathologically usual features of MF are found in MFPP but due to the spongiotic dermatitis seen in MFPP correct diagnosis might be difficult. Immunophenotyping and T-cell clonality must be analysed to confirm the diagnosis. The differential diagnosis of MFPP includes dermatophyte infections, eczema or palmoplantar psoriasis [21].

MFPP is considered as stage $1 \mathrm{~A} \mathrm{MF}$ and is treated as such giving positive clinical response to skin directed therapies like topical steroids, topical bexarotene, radiotherapy and phototherapy [22].

Pigmented Purpuric Dermatosis (PPD)-like MF (PPDMF)

PPDMF is a rare variant of MF characterised by purpuric lesions. This version of MF is reported in both adults and children, it could be seen as a lone manifestation or it could be together with other unusual subtypes of MF. Histopathologically PPDMF shows similar features to that of MF including epidermotropism with atypical lymphocytes together with the presence of siderophages typically seen in PPD [23].

Major characteristic that separates PPDMF from PPD is the distribution of the lesions. While the lesions of PPD are located mainly on the lower extremities the lesions in PPDMF is located throughout the body and may be accompanied by other types of MF lesions or large-plaque parapsoriasis. Also, in PPDMF classic patterns of MF could be seen like larger numbers of atypical lymphocytes and papillary dermal fibrosis easing the diagnosis [24].

\section{Bullous MF (BMF)}

BMF is a rare subtype of MF usually appearing a couple of months after the onset of MF or SS. The bullae in BMF tend to be tense or flaccid making it difficult to differentiate from bullous pemphigoid or pemphigus. These bullae may transform to ulcers in time effecting predominantly the trunk or the limbs. Histopathologically the blisters may be subcorneal, intraepithelial or subepidermal accompanied by typical histopathology of MF. This subtype is usually associated with a poor prognosis [25].

Other clinicopathological variations include interstitial MF, syringothrophic MF, papular and pityriasis lichenoides chronica like-MF. MF and it's subtypes could easily be mistaken as other T-cell mediated dermatosis so lesions refractory to long term treatment should be followed up closely and biopsied if Iymphoma is suspected $[2,4]$.

\section{Conclusion}

Other extremely rare clinicopathological variations of MF include interstitial MF, syringothrophic MF, papular and pityriasis lichenoides chronica like-MF. MF and it's subtypes could easily be mistaken as other T-cell mediated dermatosis so lesions refractory to long term treatment should be followed up closely and frequently biopsied if lymphoma is suspected.

Ethics

Peer-review: Internally peer-reviewed.

\section{Authorship Contributions}

Concept: B.E., Design: B.E., Data Collection or Processing: Ö.A., T.K.U., Analysis or Interpretation: Ö.A., T.K.U., Literature Search: D.D.A., Ö.A., T.K.U., B.E., Writing: D.D.A., B.E.

Conflict of Interest: No conflict of interest was declared by the authors.

Financial Disclosure: The authors declared that this study received no financial support.

\section{References}

1. Willemze R, Jaffe ES, Burg G, Cerroni L, Berti E, Swerdlow SH, Ralfkiaer E, Chimenti S, Diaz-Perez JL, Duncan LM, Grange F, Harris NL, Kempf W, Kerl H, Kurrer M, Knobler R, Pimpinelli N, Sander C, Santucci M, Sterry W, Vermeer MH, Wechsler J, Whittaker S, Meijer CJ. WHO-EORTC classification for cutaneous lymphomas. Blood 2005;105:3768.

2. Nashan D, Faulhaber D, Ständer S, Luger TA, Stadler R. Mycosis fungoides: a dermatological masquerader. Br J Dermatol 2007;156:1.

3. Ahn CS, ALSayyah A, Sangüeza OP. Mycosis fungoides: an updated review of clinicopathologic variants. Am J Dermatopathol 2014;36:933-48;quiz 94951.

4. Martínez-Escala ME, González BR, Guitart J. Mycosis Fungoides Variants. Surg Pathol Clin 2014;7:169.

5. van Doorn R, Scheffer E, Willemze R. Follicular mycosis fungoides, a distinct disease entity with or without associated follicular mucinosis: a clinicopathologic and follow-up study of 51 patients. Arch Dermatol 2002;138:191

6. Muniesa C, Estrach T, Pujol RM, Gallardo F, Garcia-Muret P, Climent J, Servitje 0 . Folliculotropic mycosis fungoides: clinicopathological features and outcome in a series of 20 cases. J Am Acad Dermatol 2010;62:418.

7. Hodak E, Amitay-Laish I, Feinmesser M, Davidovici B, David M, Zvulunov A, Pavlotsky F, Yaniv I, Avrahami G, Ben-Amitai D. Juvenile mycosis fungoides: cutaneous T-cell lymphoma with frequent follicular involvement. J Am Acad Dermatol 2014;70:993.

8. Mantaka P, Helsing P, Gjersvik P, Bassarova A, Clausen OP, Delabie J. Clinical and histopathological features of folliculotropic mycosis fungoides: a Norwegian patient series. Acta Derm Venereol 2013;93:325.

9. Gerami P, Rosen S, Kuzel T, Boone SL, Guitart J. Folliculotropic mycosis fungoides: an aggressive variant of cutaneous T-cell lymphoma. Arch Dermatol 2008;144:738 
10. van Santen S, van Doorn R, Neelis KJ, Daniëls LA, Horváth B, Bruijn MS, Sanders CJG, van Rossum MM, de Haas ERM, Veraart JCJM, Bekkenk MW, Vermeer MH, Willemze R. Recommendations for treatment in folliculotropic mycosis fungoides: report of the Dutch Cutaneous Lymphoma Group. Br J Dermatol 2017;177:223.

11. Haghighi B, Smoller BR, LeBoit PE, Warnke RA, Sander CA, Kohler S. Pagetoid reticulosis (Woringer-Kolopp disease): an immunophenotypic, molecular, and clinicopathologic study. Mod Pathol 2000;13:502.

12. Kempf W, Ostheeren-Michaelis S, Paulli M, Lucioni M, Wechsler J, Audring H, Assaf C, Rüdiger T, Willemze R, Meijer CJ, Berti E, Cerroni L, Santucci M, Hallermann C, Berneburg M, Chimenti S, Robson A, Marschalko M, Kazakov DV, Petrella T, Fraitag S, Carlotti A, Courville P, Laeng H, Knobler R, Golling P, Dummer R, Burg G; Cutaneous Lymphoma Histopathology Task Force Group of the European Organization for Research and Treatment of Cancer. Granulomatous mycosis fungoides and granulomatous slack skin: a multicenter study of the Cutaneous Lymphoma Histopathology Task Force Group of the European Organization For Research and Treatment of Cancer (EORTC). Arch Dermatol 2008;144:1609.

13. Li JY, Pulitzer MP, Myskowski PL, Dusza SW, Horwitz S, Moskowitz A, Querfeld C. A case-control study of clinicopathologic features, prognosis, and therapeutic responses in patients with granulomatous mycosis fungoides. J Am Acad Dermatol 2013;69:366.

14. Haruyama S, Sugita K, Kawakami C, Nakamura M, Tokura Y. Development of a prominent granulomatous eruption after interferon-gamma therapy in a patient with mycosis fungoides. Acta Derm Venereol 2010;90:190.

15. Vasconcelos Berg R, Valente NYS, Fanelli C, Wu I, Pereira J, Zatz R, Sanches JA. Poikilodermatous Mycosis Fungoides: Comparative Study of Clinical, Histopathological and Immunohistochemical Features. Dermatology 2020;236:117.

16. Castano E, Glick S, Wolgast L, Naeem R, Sunkara J, Elston D, Jacobson M. Hypopigmented mycosis fungoides in childhood and adolescence: a longterm retrospective study. J Cutan Pathol 2013;40:924.
17. Singh ZN, Tretiakova MS, Shea CR, Petronic-Rosic VM. Decreased CD117 expression in hypopigmented mycosis fungoides correlates with hypomelanosis: lessons learned from vitiligo. Mod Pathol 2006;19:1255.

18. Lee JS, Yun SJ, Lee JB, et al. A case of hyperpigmented mycosis fungoides: a rare variant. J Eur Acad Dermatol Venereol 2007;21:983.

19. Pavlovsky L, Mimouni D, Amitay-Laish I, Feinmesser M, David M, Hodak E. Hyperpigmented mycosis fungoides: an unusual variant of cutaneous T-cell lymphoma with a frequent CD8+ phenotype. J Am Acad Dermatol 2012;67:69.

20. Topf S, Lüftl M, Neisius U, Brabletz T, Simon M, Schuler G, Schultz E. Mycosis fungoides palmaris et plantaris--an unusual variant of cutaneous T-cell lymphoma. Eur J Dermatol 2006;16:84.

21. Spieth K, Grundmann-Kollmann M, Runne U, Staib G, Fellbaum C, Wolter M, Kaufmann R, Gille J. Mycosis-fungoides-type cutaneous T cell lymphoma of the hands and soles: a variant causing delay in diagnosis and adequate treatment of patients with palmoplantar eczema. Dermatology 2002;205:239.

22. Nakai N, Hagura A, Yamazato S, Katoh N. Mycosis fungoides palmaris et plantaris successfully treated with radiotherapy: case report and mini-review of the published work. J Dermatol 2014;41:63.

23. Martínez W, del Pozo J, Vázquez J, Yebra-Pimentel MT, Almagro M, GarcíaSilva J, Fonseca E. Cutaneous T-cell lymphoma presenting as disseminated, pigmented, purpura-like eruption. Int J Dermatol 2001;40:140.

24. Kim DH, Seo SH, Ahn HH, Kye YC, Choi JE. Characteristics and Clinical Manifestations of Pigmented Purpuric Dermatosis. Ann Dermatol 2015;27:404

25. Sato S, Okamoto O, Kawamoto M, Oishi M, Yada N, Kohno K, Yokoyama,S, Fujiwara S. Bullous mycosis fungoides associated with an extensive ulcer and a severe leukemoid reaction. Dermatol Reports 2011;3:e54. 